\title{
Directional Effects in Dielectric Properties of Molded Rubber
}

\author{
By Arnold H. Scott
}

\begin{abstract}
Slabs of rubber-filler mixtures were prepared in such a way that flow in sheeting and molding was greatly accentuated in one direction. This paper describes the method of molding and gives values of dielectric constant and dissipation factor for measurements made on a variety of mixtures in which the samples were prepared and arranged for measurements in the direction of flow during molding and in the two mutually perpendicular directions. For some mixtures the values were much higher in one direction than in the others. A possible explanation for this is given. By using cubes of the material as spacers for an optical interferometer, linear thermal expansivities were measured in three mutually perpendicular directions. Some mixtures had greater expansivities in one direction than in others, but there was no correlation with the dielectric constants and dissipation factors.
\end{abstract}

\section{Introduction}

During the course of an investigation of differently compounded rubber-filler systems. it was observed that specimens of the same composition sometimes showed large differences in their values of both dielectric constant and of dissipation factor. The most likely explanation was that these electrical properties were affected by the amount of flow in a given direction produced during manufacture of the samples. A study was therefore made of the effect of flow during molding upon the dielectric constant and dissipation factor of a number of rubber-filler mixtures. The thermal expansivity of the samples was also obtained in order to determine correlations that might exist. The results show that flow during molding may produce large differences in the dielectric constant, dissipation factor, and expansivity of certain rubber-filler mixtures.

\section{Preparation of Specimens}

In order to study the directional effect of flow during molding on these properties, a method of working and molding was used that forced the flow to be largely in one selected direction. Thus in working and mixing the rubber, the rolls produce more flow in the direction of sheeting than in the other directions. The spacing of the rolls was so adjusted that when the sheet of rubber was taken from the mill it was between 5 and $7 \mathrm{~mm}$ thick.

A mold was used that produced slabs about 0.6 $\mathrm{cm}$ thick, $14 \mathrm{~cm}$ wide and $15 \mathrm{~cm}$ long. The sheet of material that was taken from the mill was cut into strips 2 to $3 \mathrm{~cm}$ wide. The strips were cut perpendicular to the direction of major flow produced by the mill. The strips were then cut into $14 \mathrm{~cm}$ lengths so that they would just fit the width of the mold. Two of these strips were placed one on top of the other in the mold about midway of its 15 -cm length. The cover was placed on the mold and the mixture was pressed out, the flow of necessity being in the direction of its $15-\mathrm{cm}$ length. The cover was removed and another strip was placed on the pressed-out mixture in the mold again at the midpoint of its 15 -cm length. The cover was replaced, and again the mixture was pressed out. This loading and pressing process was repeated until the mold was filled. The resulting slab of rubber was then removed from the mold and again cut into strips 2 to $3 \mathrm{~cm}$ wide. These strips were also cut perpendicular to the direction of major flow. The new strips were pressed out in the mold by repeating the above process. The complete process was repeated three 
or four times. As a final step the mixture was vulcanized in the mold to form a cured slab.

The same rubber-base compound with various amounts of fillers was used in preparing two series of rubber-filler mixtures, namely, rubber-calcium carbonate and rubber-zinc oxide. The base compound had the following composition:

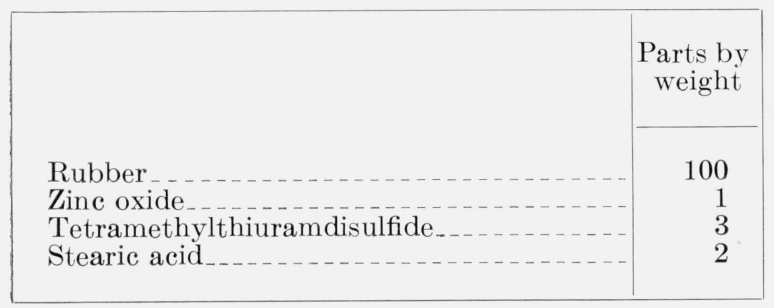

Rubber-filler mixtures other than the two series above were prepared and measured, but in some cases different compounds were used. The results of these measurements are reported along with the results for the two series.

For the following discussion we shall designate three mutually perpendicular directions as follows (see fig. 1); the $P$ direction being perpendicular to the surface of the molded slab, the $Q$ direction being the 14-cm width direction, and the $R$ direction being the 15 -cm length direction. Thus the $R$ direction is the direction of major flow during molding.

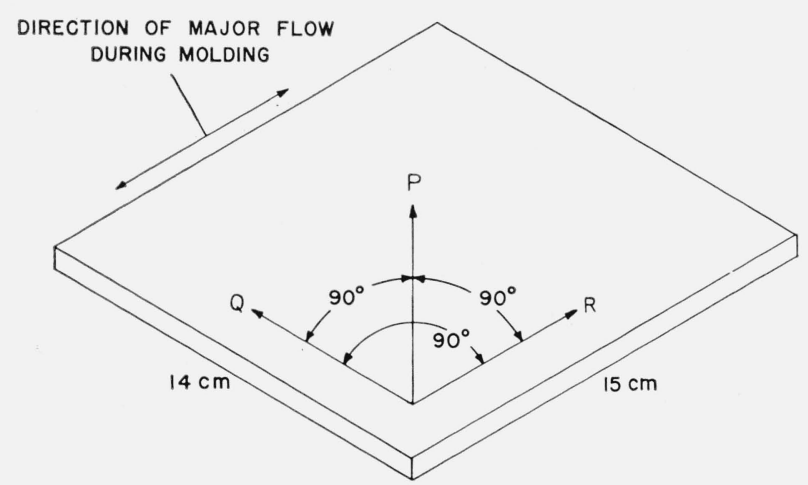

FIgURE 1. Isometric sketch defining directions $P, Q$, and $R$.

\section{Measurements of Dielectric Constant and Dissipation Factor}

The normal procedure for preparing samples for the measurement of dielectric constant and dissipation factor involves preparation of the material in the form of a sheet or slab and affixing electrodes to the opposite faces. This arrangement alines the electric field in the direction perpendicular to the faces of sheet or slab, i. e., in the $P$ direction, which, in the case of molded material, would normally be perpendicular to the direction of the flow that existed during the molding operation. A different technique must be used in the preparation of samples to permit measurements with the electric field alined in the $Q$ and $R$ directions.

The preparation of samples for electrical measurements with the field in the $Q$ and $R$ directions was similar to that used by Albert [1] ${ }^{1}$ in the case of laminated phenolic materials. The slab was cut into strips whose widths w ere approximately the same as their thickness. The normal orientation of the material was then changed by rotating each strip $90^{\circ}$ and assembling the group side by side to form a composite specimen for measurement. This technique permits measurements of the same specimen in two mutually perpendicular directions relative to the direction of the electric field by a mere rearrangement of the strips. To obtain a third measurement for the material perpendicular to the first two, another similar slab must be used with the strips cut perpendicular to those in the first slab.

The slab specimens were cut into strips $6 \mathrm{~mm}$ wide by means of a sharp knife having guided travel. The knife was raised, and the slab was placed under the knife against an adjustable stop. The knife was then lowered and sufficient force applied to force it through the specimen. A soap solution applied to the slab acted as a lubricant for the knife on its passage through the rubber.

Values of dielectric constant and dissipation factor were determined for the composite specimen by placing it between electrodes so spaced that when it rested on the bottom electrode an air gap intervened between the upper surface of the specimen and the upper electrode, as shown in figure 2. This arrangement, hereinafter called the "spaced-electrode method" for evaluating dielectric constant and dissipation factor, is similar to that described by Starling [2] but with the modification that the area of the specimen is smaller than that of the electrodes.

One of the parallel-plate electrodes was provided with a guard ring. The spacing between the electrodes could be accurately and easily adjusted. The capacitance, at an appropriate spacing, was

\footnotetext{
${ }^{1}$ Figures in brackets indicate the literature references at the end of this paper.
} 
measured before the assembled specimen was inserted. Then the capacitance and dissipation factor were measured with the specimen in place by means of the conjugate Schering bridge described in a former paper [3]. The distance between the electrodes and the thickness and area of the composite specimen were also determined. From these measurements the dielectric constant and dissipation factor of the material were computed.
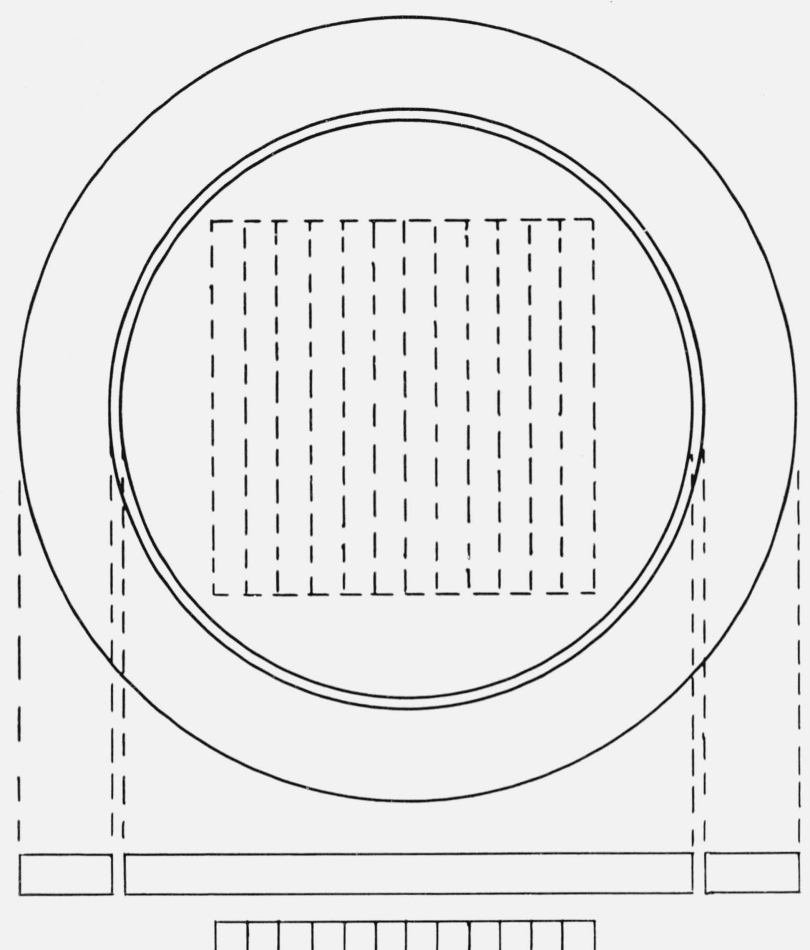

Figure 2. Position of samples between electrodes of guard ring capacitor.

Accurate computation of the dielectric constant and dissipation factor from these measurements is extremely difficult, since precise formulas are not available. After some study, it was decided that it was not worth while to spend the time and effort necessary for deriving precise formulas. So relatively simple equations were used that gave roughly approximate values. These values were plotted against the air gap distance between the specimen and the electrode, and the resulting curve was extrapolated to zero air gap. The value of the air gap was taken as the difference between the electrode spacing and the thickness of the specimen.
The roughly approximate formulas were derived on the assumption that the electric field between the electrodes is everywhere normal to their inner parallel surfaces. The capacitor unit was then considered to be a combination of three capacitances; an air capacitance in series with the specimen capacitance and another air capacitance in parallel with this series combination. The resulting formula for the approximate dielectric constant is

$$
K_{1}=\frac{\frac{1.113 A}{4 \pi t}+C_{t}-C_{a}}{\frac{1.113 A}{4 \pi t}-\frac{t-d}{d}\left(C_{t}-C_{a}\right)} .
$$

$C_{t}=$ Capacitance in micromicrofarads of unit with specimen between the electrodes.

$C_{a}=$ Capacitance in micromicrofarads of unit without specimen between the electrodes.

$d=$ Average thickness of specimen in centimeters .

$t=$ Electrode spacing in centimeters.

$A=$ Area of specimen in square centimeters.

The approximate dissipation factor is given by

$$
\tan \delta_{1}=\frac{C_{s} C_{t} \tan \delta_{t}}{C_{s} C_{b}-C_{b}^{2}}
$$

where $\tan \delta_{t}=$ the measured dissipation factor of the unit with the specimen between the electrodes

$$
C_{s}=\frac{0.08854 A}{t-d} \text { and } C_{b}=C_{t}-C_{a}+\frac{0.08854 A_{s} .}{t}
$$

$C_{s}$ can be thought of as the air capacitance, which is in series with the specimen and $C_{b}$ as the series combination of $C_{s}$ and the capacitance of the specimen.

To test the method, uncut specimens were measured both by using tinfoil electrodes in the usual manner and by the spaced-electrode method just described. Typical results are shown in figure 3 for dielectric constant and in figure 4 for dissipation factor. The short horizontal lines on the left-hand side of each graph indicate the values obtained with tinfoil electrodes. The solid dots indicate the values obtained on the solid slab when using the spaced-electrode method. The extrapolated values at zero air gap are in reasonable agreement with the values obtained with tinfoil electrodes.

The slab of rubber was cut into strips and the 
strips reassembled in their original positions so that the effect of cutting the specimen into strips could be studied. The results are shown as crosses in figures 3 and 4 . These computed values are more dependent on the thickness of the air gap than were those for the solid slab. The value at zero air gap was somewhat lower than the value obtained with tinfoil electrodes. However, the agreement between these values is sufficiently good to reveal much larger differences that were obtained when the strips were rotated through $90^{\circ}$. The results of these measurements are shown as open circles in figures 3 and 4 . The intercepts at zero air gap of the curves through these points are considered to be the significant values for the $Q$ and $R$ directions.

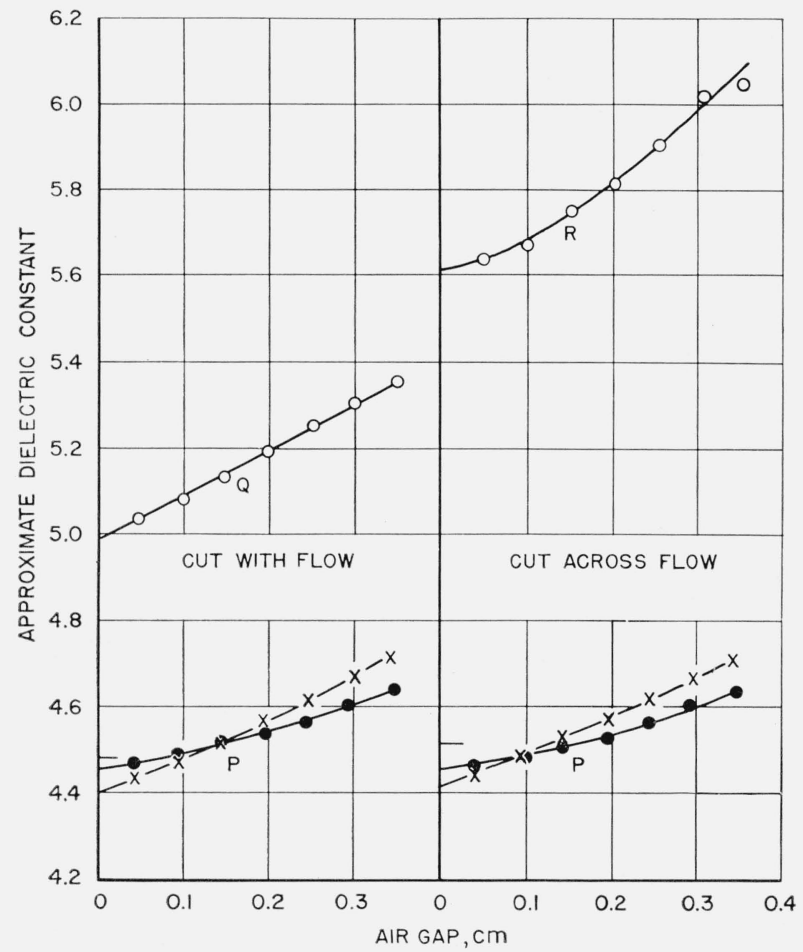

FIGURE 3. Effect of air gap on dielectric constant measurement.

75 percent of $\mathrm{ZnO}$. Uncut; $\mathrm{X}$, as cut; $\bigcirc$, turned.

\section{Dimensional Measurements}

The volume of the slab specimen was determined by weighing in air and in water. The length and breadth of the specimen were measured with a steel scale, and an average of several readings was used in the computations. From these the surface area was determined. The thickness was computed by dividing the volume by the area.

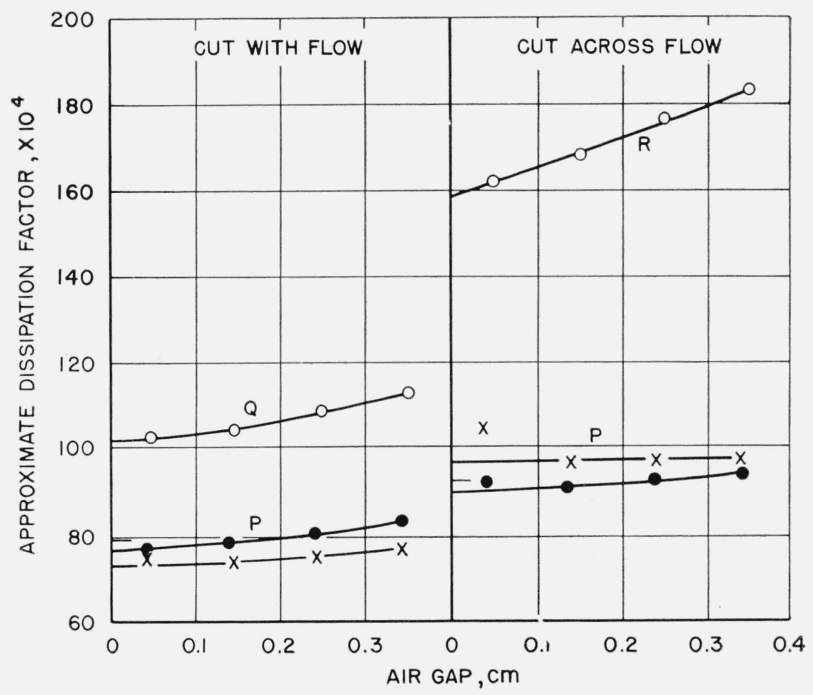

Figure 4. Effect of air gap on dissipation factor measurement.

75 percent of $\mathrm{ZnO}$. $\bullet$, Uncut; $\mathrm{X}$, as cut; $\bigcirc$, turned.

After the strips had been cut, the volume was again determined from hydrostatic weighings. The average length of the strips was known, as was the average thickness. The average width of the strips was computed by dividing the volume by the product of length, thickness, and number of strips. When the strips were turned edge on in the capacitor unit, this average width was used as the thickness for computations.

The weighings that were made for the purpose of determining the volume of the slabs and the strips cut from them also served for the determination of the density. The densities of the individual strips agreed closely with the density of the slabs, showing that there was no significant inhomogeneity such as might have resulted from incomplete mixing of the filler or from trapped air. By way of illustration, a slab containing 70 percent of zinc oxide showed a density of 2.2413 ; whereas the mean values for the strips cut from the slab were 2.2410 , and the maximum spread between values was 0.0010 .

The density of this slab was also compared with the density calculated from the composition. The calculated density was 2.242 and differs by only 0.001 from the observed density. The difference is judged to be within the experimental error, which involves not only the errors in the determination of density but also uncertainties arising in the compounding process and in the values used for densities of the ingredients. 
This relatively good agreement between the calculated and the observed density of the rubber compound is considered to show that the filler was well dispersed. If the filler had been present in the form of clumps of particles or agglomerates, the voids between the particles would have reduced the density by a significant amount.

\section{Determination of Expansivity}

The linear thermal expansivity was determined by the interferometer method described by Wood, Bekkedahl, and Peters [4], in which the plates of an interferometer are separated by three cubes of the material to be measured. The plate assembly was mounted in a metal case, which was placed in a temperature-controlled bath. A number of cubes were cut, and three were selected that would give sufficiently broad fringes for the measurement. The measurement involves counting fringes as they pass the cross hair while the temperature is being changed from one value to another. The expansivity can be computed from the number of fringes counted for the temperature change, the value of the wavelength of the light used, and the thickness of the samples.

A change either in direction of the fringes or in the spacing between fringes indicates either differences in temperatures of the cubes, tilting of the cubes, or nonuniformity of expansion of the material being measured. Small differences that were observed were attributed to nonuniformity of expansion. The good agreement noted above between the density of the entire slab and that of strips cut from it indicates that this nonuniformity probably does not result from uneven or incomplete mixing of the filler with the rubber. The nonuniformity may be caused by irregular flow during the molding operation such that the fine structure, which is assumed to be present and to be responsible for the directional effect, differs in orientation in some parts of the slab. Another factor that could contribute to the nonuniform expansion could arise from the presence of nonuniform residual stresses in the rubber. It is well known that even small stresses may significantly alter the way in which rubber changes in dimensions with temperature.

\section{Results}

The dielectric constant and dissipation factor were determined in most cases on two slabs of each composition prepared from a single mixture. Thus, for most of the compositions, there are duplicate measurements in the $P$ direction and single measurements in the $Q$ direction and in the $R$ direction. For two of the compositions, three slabs were made so that there were triplicate measurements in the $P$ direction and duplicate measurements in one of the other directions. For six of the compositions, only single slabs were prepared so that measurements could be made in only the $P$ direction and one other direction.

In table 1 columns 5,6 , and 7 , values for the $P$ direction are reported for measurements made (5) with tinfoil electrodes, (6) with spaced electrodes and the specimen uncut, and (7) with spaced electrodes and the specimen cut. If the values obtained with the tinfoil electrodes (col. 5) are assumed to be correct, then the differences between corresponding values in column 5 and columns 6 and 7 are suggestive of the accuracy limitations of the spaced-electrode method for evaluating the dielectric constant and dissipation factor of the strips.

TABLE 1. Dielectric constant of rubber-filler mixtures

The values given in this table are single determinations. Samples of the same composition were prepared from a single batch.

\begin{tabular}{|c|c|c|c|c|c|c|c|c|}
\hline \multirow{4}{*}{$\begin{array}{c}\text { Sam- } \\
\text { ple } \\
\text { num- } \\
\text { ber }\end{array}$} & \multirow{4}{*}{ Filler } & \multirow{4}{*}{$\begin{array}{l}\text { Per- } \\
\text { cent- } \\
\text { age of } \\
\text { filler } \\
\text { by } \\
\text { weight }\end{array}$} & \multirow{4}{*}{$\begin{array}{c}\text { Fre- } \\
\text { quen- } \\
\text { cy }\end{array}$} & \multicolumn{5}{|c|}{ Dielectric constant } \\
\hline & & & & \multicolumn{3}{|c|}{$P$ direction } & \multirow{3}{*}{$\begin{array}{c}Q \\
\text { direc- } \\
\text { tion }\end{array}$} & \multirow{3}{*}{$\begin{array}{c}R \\
\text { direc- } \\
\text { tion }\end{array}$} \\
\hline & & & & \multirow{2}{*}{$\begin{array}{c}\text { Tin- } \\
\text { foil } \\
\text { elec- } \\
\text { trodes }\end{array}$} & \multicolumn{2}{|c|}{$\begin{array}{c}\text { Spaced } \\
\text { electrodes }\end{array}$} & & \\
\hline & & & & & $\begin{array}{l}\text { Un- } \\
\text { cut }\end{array}$ & Cut & & \\
\hline 1 & & 0 & $k c_{1}$ & & & 2.57 & 2,57 & \\
\hline 1 & $\ldots$ & 0 & 100 & 2.54 & & 2.55 & 2.55 & .... \\
\hline 2 & & 0 & 1 & & & 2.56 & & 2.58 \\
\hline 2 & 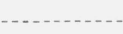 & 0 & 100 & 2.53 & - n & 2.55 & & 2.57 \\
\hline 3 & $\mathrm{CaCO}_{3} \ldots$ & 25 & 1 & 2.91 & & 2. 91 & 2.93 & $\ldots$ \\
\hline 3 & $\mathrm{CaCO}_{3} \ldots$ & 25 & 100 & 2.89 & & 2.90 & 2. 93 & …- \\
\hline 4 & $\mathrm{CaCO}_{3 \ldots} \ldots$ & 25 & 1 & 2.90 & & 2. 92 & & 2.97 \\
\hline 4 & $\mathrm{CaCO}_{3} \ldots$ & 25 & 100 & 2.88 & & 2. 92 & $\ldots$ & 2.96 \\
\hline 5 & $\mathrm{CaCO}_{3} \ldots$ & 75 & 1 & & & 4.81 & 4.81 & - \\
\hline 5 & $\mathrm{CaCO}_{3} \ldots$ & 75 & 100 & & & 4.80 & 4. 79 & - n \\
\hline 6 & $\mathrm{CaCO}_{3} \ldots$ & 75 & 1 & & & 4.82 & & 4.86 \\
\hline 6 & $\mathrm{CoCO}_{3} \ldots$ & 75 & 100 & - & & 4. 79 & $-\cdots-$ & 4.83 \\
\hline 7 & $\mathrm{ZnO}$ & 40 & 1 & 3.04 & & 3.05 & 3.28 & - - \\
\hline 7 & $\mathrm{ZnO}$ & 40 & 100 & 3.00 & & 3.02 & 3.20 & - \\
\hline 8 & $\mathrm{ZnO}$ & 40 & 1 & 3.02 & & 3.05 & & 3.38 \\
\hline 8 & $\mathrm{ZnO}$ & 40 & 100 & 3.00 & & 3.01 & - & 3. 29 \\
\hline
\end{tabular}


TABLE 1. Dielectric constant of rubber-filler mixtures-Con.

\begin{tabular}{|c|c|c|c|c|c|c|c|c|}
\hline \multirow{4}{*}{$\begin{array}{c}\text { Sam- } \\
\text { ple } \\
\text { num- } \\
\text { ber }\end{array}$} & \multirow{4}{*}{ Filler } & \multirow{4}{*}{$\begin{array}{c}\text { Per- } \\
\text { cent- } \\
\text { age of } \\
\text { filler } \\
\text { by } \\
\text { weight }\end{array}$} & \multirow{4}{*}{$\begin{array}{l}\text { Fre- } \\
\text { quen- } \\
\text { cy }\end{array}$} & \multicolumn{5}{|c|}{ Dielectric constant } \\
\hline & & & & \multicolumn{3}{|c|}{$P$ direction } & \multirow{3}{*}{$\begin{array}{l}Q \\
\text { direc- } \\
\text { tion }\end{array}$} & \multirow{3}{*}{$\begin{array}{l}R \\
\text { direc- } \\
\text { tion }\end{array}$} \\
\hline & & & & \multirow{2}{*}{\begin{tabular}{|c|} 
\\
Tin. \\
foil \\
elec- \\
trodes
\end{tabular}} & \multicolumn{2}{|c|}{$\begin{array}{l}\text { Spaced } \\
\text { electrodes }\end{array}$} & & \\
\hline & & & & & $\begin{array}{l}\text { Un- } \\
\text { cut }\end{array}$ & Cut & & \\
\hline 9 & $\mathrm{ZnO}_{-}$ & 60 & ${ }^{k c}{ }_{1}$ & 3.71 & & 3. 70 & 4.05 & \\
\hline 9 & $\mathrm{ZnO}$ & 60 & 100 & 3. 63 & & 3. 62 & 3.92 & \\
\hline 10 & $\mathrm{ZnO}_{-}$ & 60 & 1 & 3.65 & & 3.64 & & 4. 26 \\
\hline 10 & $\mathrm{ZnO} \ldots$ & 60 & 100 & 3.58 & & 3.57 & & 4. 12 \\
\hline 11 & $\mathrm{ZnO} \ldots$ & 70 & 1 & 4.11 & 4.08 & 4. 07 & & 5.12 \\
\hline 11 & $\mathrm{ZnO}_{\ldots}$ & 70 & 100 & 4.03 & 4.00 & 4. 01 & $\ldots$ & 4. 84 \\
\hline 12 & $\mathrm{ZnO}_{-}$ & 75 & 1 & 4.47 & 4. 46 & 4. 39 & 5.00 & - \\
\hline 12 & $\mathrm{ZnO}$ & 75 & 100 & 4.36 & 4. 35 & 4. 30 & 4. 79 & -...- \\
\hline 13 & $\mathrm{ZnO}_{\ldots}$ & 75 & 1 & 4. 51 & 4. 48 & 4. 43 & & 5.62 \\
\hline 13 & $\mathrm{ZnO}_{\ldots} \ldots$ & 75 & 100 & 4. 40 & 4. 32 & 4. 31 & & 5. 21 \\
\hline 14 & $\mathrm{ZnO} \ldots$ & 75 & 1 & 4.45 & 4. 40 & 4. 46 & & 5.68 \\
\hline 14 & $\mathrm{ZnO}$ & 75 & 100 & 4. 45 & 4. 29 & 4. 35 & & 5.35 \\
\hline 15 & $\mathrm{TiO}_{2 .}$ & 75 & 1 & 8.97 & & 8.60 & 9. 55 & -..... \\
\hline 15 & $\mathrm{TiO}_{2} \ldots$ & 75 & 100 & 8.82 & & 8.43 & 9.54 & ..... \\
\hline 16 & $\mathrm{TiO}_{2-}$ & 75 & 1 & 8.97 & & 8.52 & & 9. 98 \\
\hline 16 & $\mathrm{TiO}_{2-}$ & 75 & 100 & 8.83 & & 8.43 & & 9.83 \\
\hline 17 & $\mathrm{TiO}_{2-}$ & 75 & 1 & 9.05 & & 8.40 & & 10.10 \\
\hline 17 & $\mathrm{TiO}_{2 \ldots} \ldots$ & 75 & 100 & 8.91 & & 8.28 & ... & 9.89 \\
\hline 18 & $\mathrm{Al}_{2} \mathrm{O}_{3-\ldots}$ & 53.4 & 1 & 3.65 & & 3. 59 & & 3.89 \\
\hline 18 & $\mathrm{Al}_{2} \mathrm{O}_{3} \ldots$ & 53.4 & 100 & 3.51 & & 3. 47 & & 3.62 \\
\hline 19 & $\mathrm{Fe}_{2} \mathrm{O}_{3} \ldots$ & 75 & 1 & 6.05 & & 6.10 & & 6.58 \\
\hline 19 & $\mathrm{Fe}_{2} \mathrm{O}_{3 \ldots} \ldots$ & 75 & 100 & 5.62 & & 5. 62 & & 6.00 \\
\hline 20 & $\mathrm{PbO}_{\ldots}$ & 87.2 & 1 & 6.98 & & 7.00 & 14.1 & ...... \\
\hline 20 & $\mathrm{PbO}$ & 87.2 & 100 & 6.26 & & 6.05 & 11.0 & -.... \\
\hline 21 & $\mathrm{PbO} \ldots$ & 87.2 & 1 & 6. 96 & & 7.1 & & 18.4 \\
\hline 21 & $\mathrm{PbO}_{2}$ & 87.2 & 100 & 6.25 & & 6.1 & & 12.9 \\
\hline 22 & $\int \mathrm{PbO}_{-}$ & 43.7 & 1 & 5.95 & & 5.65 & 10.1 & .... \\
\hline 22 & $\mathrm{ZnO}$ & 43.7 & 100 & 5.85 & & 5. 55 & 9.4 & ..... \\
\hline 23 & {$[\mathrm{PbO} \ldots$} & 43.7 & 1 & 6.16 & & 6.0 & & 12. 95 \\
\hline 23 & $\left\{\mathrm{ZnO}_{\ldots} \ldots\right.$ & 43.7 & 100 & 5.77 & & 5.55 & & 12.1 \\
\hline 24 & $\left\{\begin{array}{l}\mathrm{Fe}_{2} \mathrm{O}_{3 \ldots} \\
\mathrm{PbO}_{\ldots}\end{array}\right.$ & $\begin{array}{l}27.07 \\
49.0\end{array}$ & 1 & 5. 24 & & 5. 24 & & 8.8 \\
\hline 25 & $\left\{\begin{array}{l}\text { Carbon black } \\
\mathrm{Fe}_{2} \mathrm{O}_{3} \\
\mathrm{PbO}\end{array}\right.$ & $\begin{array}{c}3.5 \\
24.9 \\
45.16\end{array}$ & 1 & 6.85 & & 6.7 & & 10.85 \\
\hline 26 & $\left\{\begin{array}{l}\text { Carbon black } \\
\mathrm{Fe}_{2} \mathrm{O}_{3} \\
\mathrm{PbO}\end{array}\right.$ & $\begin{array}{r}7.84 \\
22.32 \\
40.32\end{array}$ & 1 & 8.0 & & 8.15 & & 12.5 \\
\hline 27 & $\left\{\begin{array}{l}\text { Carbon black } \\
\mathrm{Fe}_{2} \mathrm{O}_{3} \\
\mathrm{PbO}\end{array}\right.$ & $\begin{array}{l}13.29 \\
18.95 \\
34.44\end{array}$ & 1 & 13.7 & & 14.0 & & 22.7 \\
\hline 28 & $\left\{\begin{array}{l}\text { Carbon black } \\
\mathrm{PbO}\end{array}\right.$ & $\begin{array}{l}11.5 \\
59.56\end{array}$ & 1 | & 14.9 & & 15.4 & & 26.9 \\
\hline
\end{tabular}

Tables 1 and 2 serve to show the effect of orientation to direction of flow during molding on values of dielectric constant and dissipation factor for different mixture combinations. For specimens containing no filler and those containing calcium carbonate, the differences are small. Although the values in the $R$ direction are always slightly larger than those in the $P$ direction, the differences are probably too small to be significant. For other specimens and fillers large differences are apparent, the value of the dielectric constant in the $R$ direction being twice that in the $P$ direction in several cases. Similar differences arise in the case of values of dissipation factor. Quantitative correlation of dielectric properties with measurement of either flow or filler particle orientation, which might be expected to result therefrom, was not attempted because of the difficulties attending quantitative measurements of either.

In an earlier paper [3] it was pointed out that the dielectric constant of rubber-calcium carbonate mixtures could be given by an equation developed by Weiner [5] for conductivity. Although other equations have been proposed [6], [7], [8], and [9], the equation of Weiner seemed to be the most useful. Replacing the conductivity in Weiner's equation by $K$ we have

$$
\frac{K-K_{1}}{K+F K_{1}}=V_{2} \frac{K_{2}-K_{1}}{K_{2}+K F_{1}}
$$

or

$$
K=\frac{K_{1}\left[K_{2}+F K_{1}+V_{2} F\left(K_{2}-K_{1}\right)\right]}{K_{2}+F K_{1}-V_{2}\left(K_{2}-K_{1}\right)},
$$

where $K, K_{1}$, and $K_{2}$ are the dielectric constants of the mixture, continuous phase (rubber), and the disperse phase (filler), respectively, $V_{2}$ is the volume fraction of the dispersed phase, and $F$ is a characteristic constant that is zero if there is a series distribution of the components, becomes infinity if there is a parallel distribution of components, and is 2 for spheres embeded in a continuous medium.

Wachholtz and Franceson [10] have shown that for a dispersion of pigments in oil, the value of $F$ depends on the shape of the pigment particle. They found that for zinc oxide the value of $F$ was 2.55. But in that case the orientation was random, and the dielectric constant was the same in all three directions.

Values of $F$ in the $P, Q$, and $R$ directions were computed for the rubber-zinc-oxide series using a 
TABLE 2. Dissipation factor of rubber-filler mixtures

The values given in this table are single determinations. Samples of the same composition were prepared from a single batch.

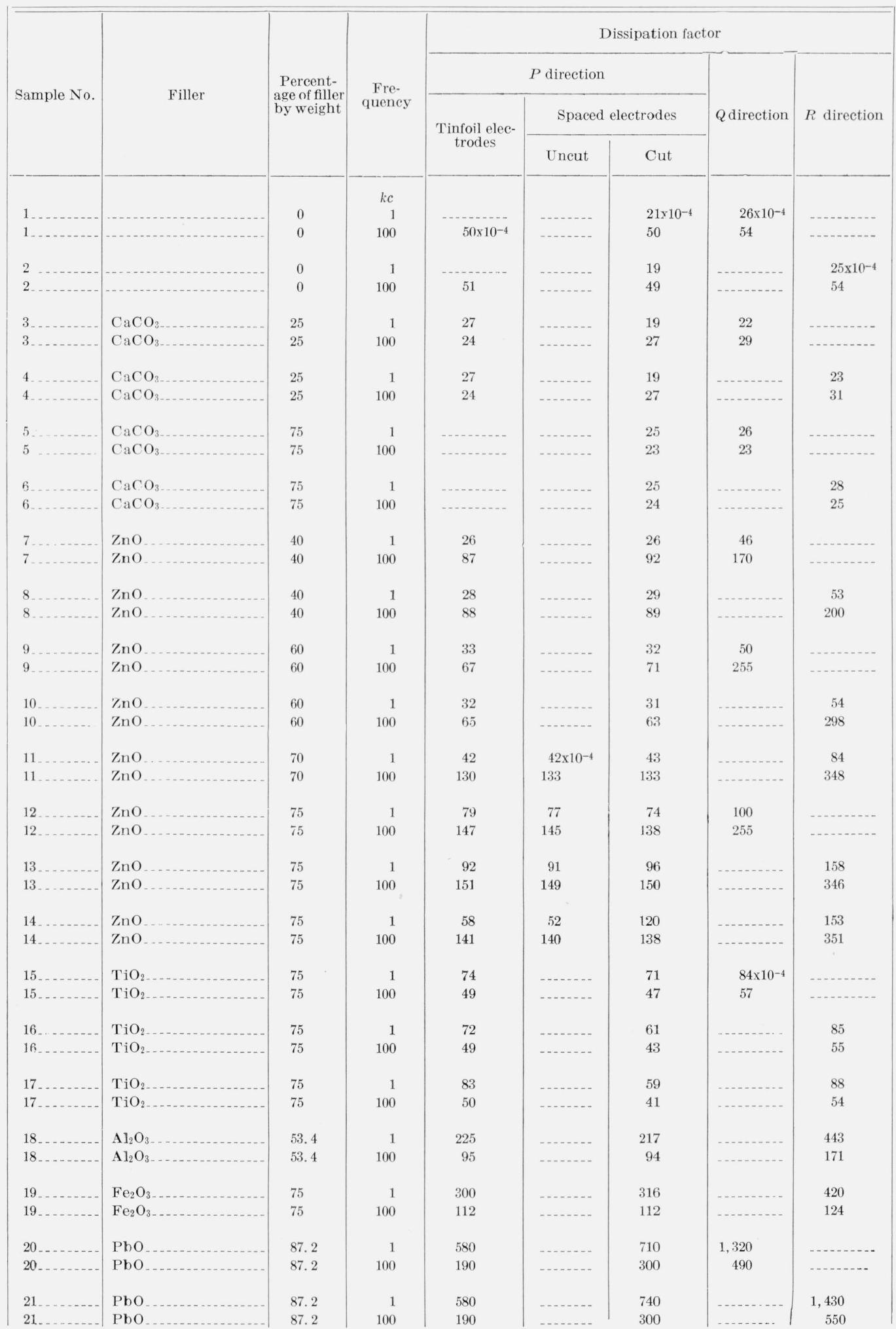


TABLE 2. Dissipation factor of rubber-filler mixtures-Continued

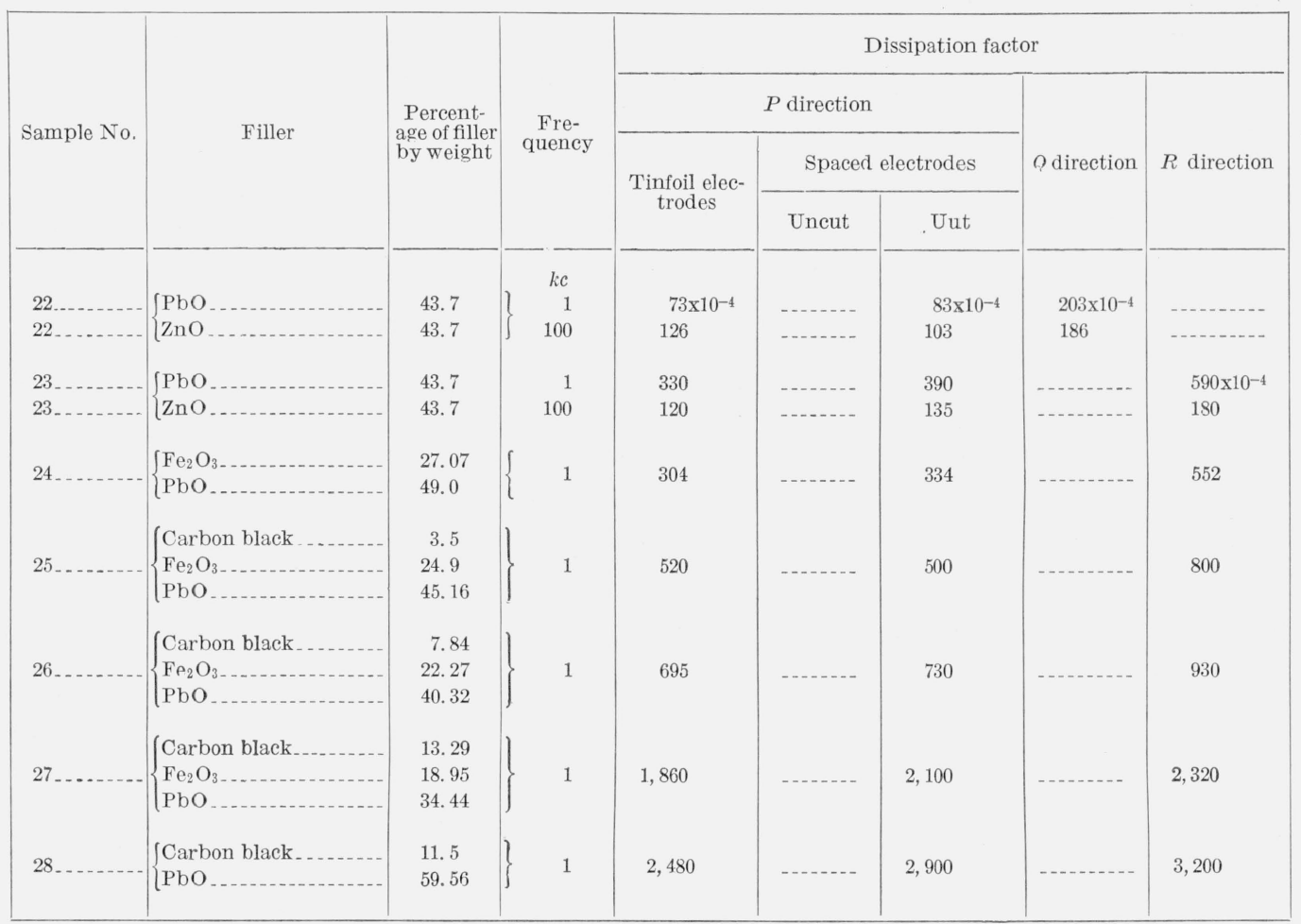

value of 34 for the dielectric constant of powdered zinc oxide at $1 \mathrm{kc}$ and 25.5 at $100 \mathrm{kc}$. The value of the dielectric constant of zinc-oxide powder at $1 \mathrm{kc}$ was obtained by the method of mixture previously described [3]. Accurate data for the dielectric constant of zinc-oxide powder at $100 \mathrm{kc}$ are not available, so a value of 25.5 was assumed, as this gave the same value of $F$ at $100 \mathrm{kc}$ as was obtained at $1 \mathrm{kc}$. Although the values of $F$ tended to decrease with increasing percentages of zinc oxide, an average value of $\mathrm{F}$ was assumed and this was used in preparing the curves shown in Figure 5. The values of $\mathrm{F}$ are shown for each curve. There is fair agreement between the curves and the measured values represented by the plotted points.

The value of $F$ (2.55 in the $R$ direction) in the direction of flow is the same as that obtained by Wachholtz and Franceson for random orientation of zinc-oxide particles. The values in the other two directions are much smaller. Wachholtz and Franceson tried to orient the zinc-oxide cyrstals by creating flow in their oil suspension but found that they could lower the value of $F$ only 0.019 . It is possible however that the forces tending to aline the particles are much greater in the case of flow- ing rubber and that the final alinement is more nearly complete for the rubber-filled mixtures. The zinc oxide that was used was Kadox, and the manufacturer had determined that the particles were elongated, having a ratio of axes of 1.8. An X-ray examination of the sample containing 75 percent of zinc oxide revealed that there was considerable alinement of zinc-oxide crystals. However, the X-ray examination of the sample containing 75 percent of titanium oxide did not reveal any alinement of titanium-oxide crystals, although this specimen did show a directional effect for dielectric constant. The specimen containing litharge appeared to show some alinement of litharge cystals, but the X-ray pattern was poorly defined.

Dissipation factors for the rubber-zinc-oxide series are plotted in figure 6 against the percentage of filler. The curves for $100 \mathrm{kc}$ are much higher and have quite a different shape than those for 1 kc. No general relationship has been found between the dissipation factor and the percentage of filler.

The values of linear thermal expansivity for some of the rubber-filler mixtures are given in table 3. The volume expansivity is given in the last column and serves as a check on the accuracy 
of the measurements of linear expansivity. For the specimens containing no filler, the sum of the linear expansivities in the three directions agrees closely with the volume expansivity. A similar agreement was obtained in earlier investigations. Because of difficulties encountered in getting precise and reproducible measurements on the specimens containing fillers, differences between the sum of the linear expansivities and the volume expansivities, which range from -20 to $+37 \times$ $10^{-6}$, are considered to lie within experimental error.
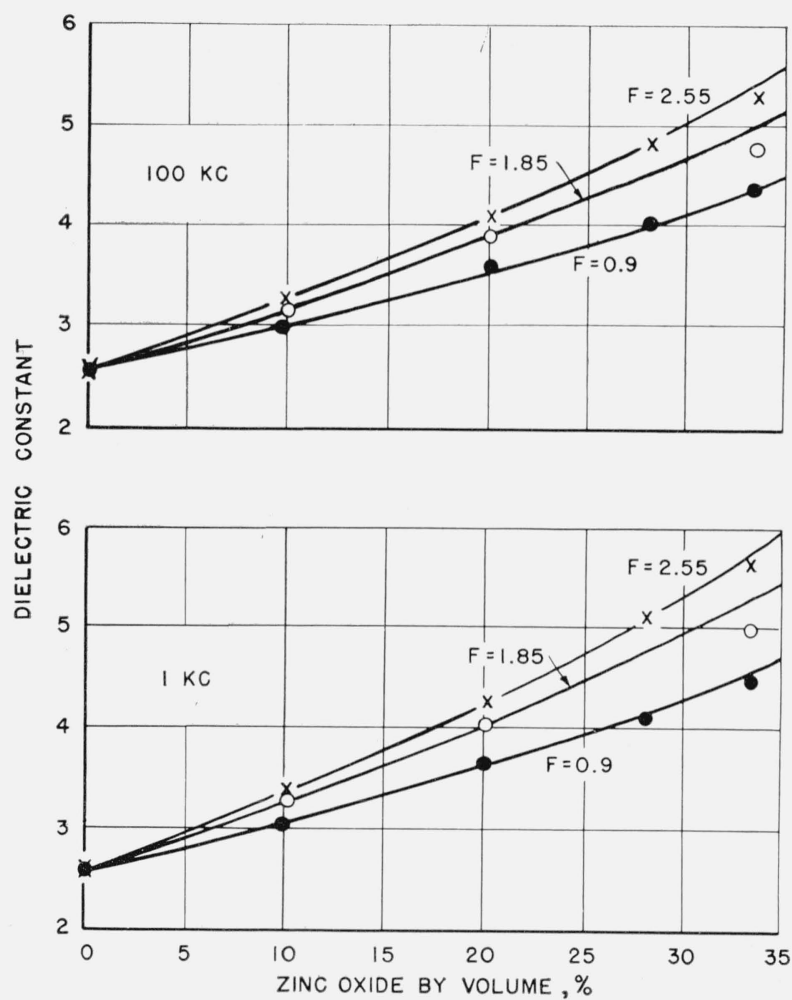

Figure 5. Comparison of computed and measured values of dielectric constant of rubber-zinc oxide mixtures at 1 and $100 \mathrm{kc}$.

The curves represent computed values. The points are experimental - $P$ direction; $\mathrm{O}, Q$ direction; $\mathrm{X}, R$ direction.

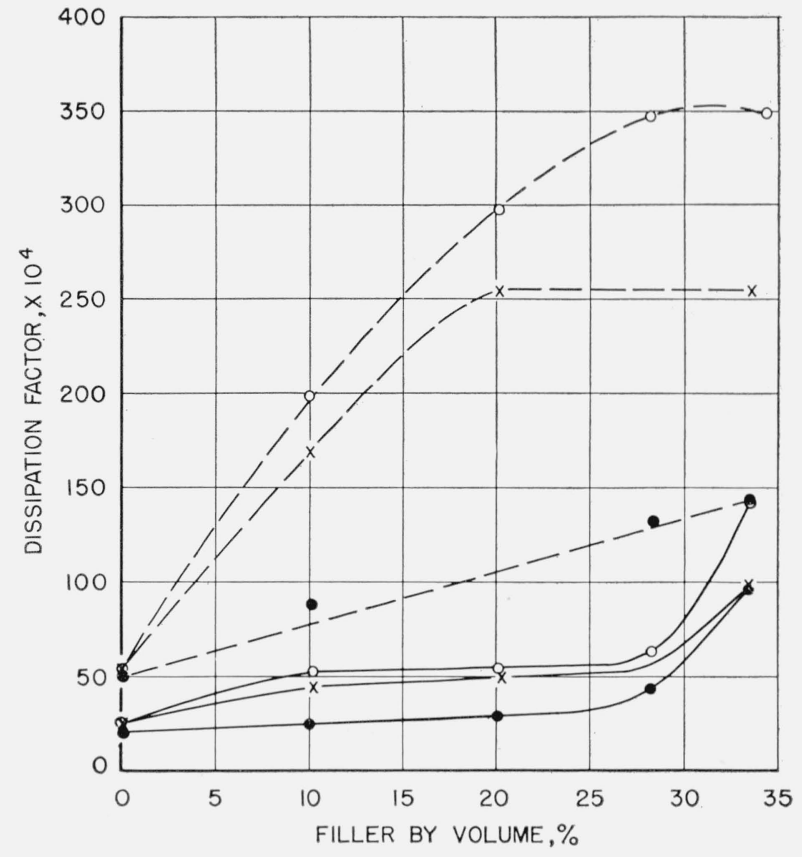

Figure 6. Dissipation factor as a function of percentage of zinc oxide by volume.

$\longrightarrow, 1,000 \mathrm{cps} ;-\longrightarrow-, 100 \mathrm{ke} / \mathrm{sec} ; \boldsymbol{\bullet}, P$ direction; $\mathrm{X}, Q$ direction; $\mathrm{O}, R$ direction.

The directional effect in expansivity was compared with the directional effect in dielectric constant and dissipation factor in seeking a possible correlation. In all instances in which significant differences in dielectric constant and in dissipation factor with direction were observed, the values were lowest in the $P$ direction. In all instances in which the differences in expansivity with direction were observed, the value in the $P$ direction was the highest. These results are consistent with the hypothesis that the filler particles are so distributed or oriented in the rubber matrix that their long axes lie in the $R$ direction. This would lead one to expect lower dielectric constant and dissipation factor in the $P$ direction than in the $R$ direction in accordance with eq 4 for dielectric

TABLE 3. Expansivity of rubber-filler mixtures

\begin{tabular}{|c|c|c|c|c|c|c|c|}
\hline \multirow{2}{*}{ Filler } & \multirow{2}{*}{$\begin{array}{l}\text { Percent- } \\
\text { age of } \\
\text { filler by } \\
\text { weight }\end{array}$} & \multicolumn{3}{|c|}{ Linear thermal expansivity } & \multirow{2}{*}{$\begin{array}{l}\text { Sum of linear } \\
\text { expansivities }\end{array}$} & \multirow{2}{*}{$\begin{array}{c}\text { Volume } \\
\text { thermal } \\
\text { expansivity }\end{array}$} & \multirow{2}{*}{$\begin{array}{c}\text { Linear } \\
\text { minus } \\
\text { volume }\end{array}$} \\
\hline & & $P$ direction & $O$ direction & $R$ direction & & & \\
\hline & 0 & $231 \times 10^{-6}$ & $223 \times 10^{-6}$ & $215 \times 10^{-6}$ & $669 \times 10^{-6}$ & $670 \times 10^{-6}$ & $-1 \times 10^{-6}$ \\
\hline $\mathrm{ZnO}$ & 40 & 219 & 204 & 202 & 625 & 588 & +37 \\
\hline $\mathrm{ZnO}$ & 75 & 195 . & 122 & 128 & 445 & 426 & +19 \\
\hline $\mathrm{TiO}_{2} \ldots . .$. & 75 & 129 & 132 & 135 & 396 & 416 & -20 \\
\hline $\mathrm{PbO}_{\ldots} \ldots . .$. & 80.4 & 166 & 81 & 120 & 367 & 384 & -17 \\
\hline
\end{tabular}


constant. It would also lead one to expect higher expansivity in the $P$ direction, because the longer length of the filler particles in the $R$ direction would tend to restrict the expansivity of the rubber in that direction since the filler has a lower expansivity than the rubber.

This hypothesis is supported by data for the compounds containing zinc oxide and litharge as fillers. On the other hand, the compound containing titanium dioxide as a filler shows a definite directional effect in dielectric constant and dissipation factor without any significant difference in expansivity along the different axes, whereas the compound containing no filler shows a quite small but probably real directional effect in expansivity without any corresponding effect in the dielectric constant and with only a small effect in the dissipation factor. Thus it appears that although the hypothesis suggested seems to afford a partial explanation, it is not completely satisfactory, probably because other significant factors have not been taken into account.

The fact that flow during molding produces a structure in which the dielectric constant and dissipation factor are greater in the direction of flow than in the other directions, may be important in cable manufacture. The extrusion of the rubber when applied to the conductor produces flow along the length of the conductor and may thus orient the filler particles in such a way that the dielectric constant in the radial direction from the conductor is different from that in the direction along the length of the conductor. Where it occurs, this directional effect should be advantageous, because the dielectric constant would be less in the direction radial from the conductor than in the other direction, and low dielectric constant is often desired. It is conceivable that an extrusion head could be designed to take maximum advantage of this effect in cable manufacture.

The author is indebted to A. T. McPherson for his many valuable suggestions and guidance in the preparation of the specimens, also to Alan $\mathrm{H}$. Selker for the preparation of many of the specimens.

\section{References}

[1] Gerard A. Albert, Dielectric loss measurements parallel to laminations, J. Applied Phys. 8, 218 (1937).

[2] Sidney G. Starling, Electricity and magnetism, p. 166 (Longmans, Green \& Co., New York, N. Y., 1918).

[3] Arnold H. Scott and Archibald T. MePherson, J. Research NBS 28, 279 (1942) RP1457.

14] L. A. Wood, N. Bekkedahl, and C. G. Peters, J. Research NBS 23, 571 (1939) RP1253.

[5] O. Weiner, Abhandl. Math.-Phys. Klasse sachs. Akad. Wiss. (Leipzig) 32, 507 (1913).

[6] J. W. Rayleigh, Phil. Mag. 34, 481 (1892).

[7] K. Lichtenecher, Physik Z. 27, 115 (1926).

[8] D. A. G. Bruggeman, Ann. Physik 24, 636 (1935).

[9] Andries Voet, J. Phys. Chem. 51, 1037 (1947).

[10] F. Wachholtz and A. Franceson, Kolloid Z. 92, 75 (1940).

Washington, May 6, 1949. 